\title{
BMJ Open Weight gain in Chinese youth during a 4-month COVID-19 lockdown: a retrospective observational study
}

\author{
Yaoshan Dun, ${ }^{1,2,3}$ Jeffrey W. Ripley-Gonzalez, ${ }^{1}$ Nanjiang Zhou, ${ }^{1}$ Baiyang You, ${ }^{1}$ \\ Qiuxia Li, ${ }^{1}$ Hui Li, ${ }^{1}$ Wenliang Zhang, ${ }^{1}$ Randal J. Thomas, ${ }^{3}$ Thomas P. Olson, ${ }^{3}$ \\ Jie Liu, ${ }^{4}$ Yuchen Dong, ${ }^{5}$ Suixin Liu (i) ${ }^{1,2}$
}

To cite: Dun Y, RipleyGonzalez JW, Zhou N, et al. Weight gain in Chinese youth during a 4-month COVID-19 lockdown: a retrospective observational study. BMJ Open 2021;11:e052451. doi:10.1136/ bmjopen-2021-052451

- Prepublication history and additional supplemental material for this paper are available online. To view these files, please visit the journal online (http://dx.doi.org/10.1136/ bmjopen-2021-052451).

Received 15 April 2021 Accepted 08 July 2021

Check for updates

(C) Author(s) (or their employer(s)) 2021. Re-use permitted under CC BY-NC. No commercial re-use. See rights and permissions. Published by BMJ.

For numbered affiliations see end of article.

Correspondence to

Prof. Suixin Liu;

liusuixin@csu.edu.cn

\section{ABSTRACT}

Objectives To observe the weight change in Chinese youth during a 4-month COVID-19 lockdown, and the association between weight change and mental health, physical activity and sedentary time changes, and dietary habits.

Design A retrospective observational study.

Settings Two universities located in Zhejiang and Hunan provinces, China.

Participants This study enrolled 12889 college students whose body weight was measured before the lockdown (1 December 2019-20 January 2020) at the two universities, and reported their weight measured at home or community after the end of the lockdown (1-23 May 2020) via an online follow-up questionnaire.

Primary and secondary outcome measures The primary outcome was the weight change in Chinese youth during a 4-month lockdown resulting from the COVID-19 pandemic. The secondary outcomes were the relationships of weight change to COVID-19-related stress, depression, anxiety, physical activity and sedentary time changes, and dietary habits.

Results Participants' ages ranged from 17 to 27 years $(M=19, \mathrm{SD}=1)$ with $80.2 \%$ identified as female. The average absolute and relative changes in body weight were $2.6(95 \% \mathrm{Cl} 2.0$ to 3.2)) $\mathrm{kg}$ and $4.2 \%(95 \% \mathrm{Cl} 4.0 \%$ to $4.3 \%$ ) for men, and 2.1 (1.9 to 2.4$) \mathrm{kg}$ and $4.2 \%$ (95\% $\mathrm{Cl} 3.9 \%$ to $4.4 \%$ ) for women. An increase in overweight and obese individuals according to Asian cut-off points as a demographic percentage by $4.5 \%$ and $2.7 \%$ and $4.8 \%$ and $3.4 \%$ in men and women, respectively $(P<0.001)$, was observed. Weight gain was significantly associated with increased sedentary time and an increase in COVID-19related stress and depression score.

Conclusion The present study's results suggest that the risk of weight gain in Chinese youth during the lockdown increased and that strategies to decrease sedentary time and improve mental health may be warranted to mitigate weight gain during and after the COVID-19 pandemic.

\section{INTRODUCTION}

The sudden emergence of COVID-19 has reverberated the world over, pushing peoples and governments into the unchartered territories of countrywide lockdowns and social distancing. On 20 January 2020, China issued a national
Strengths and limitations of this study

- The occurrence of weight gain during a 4-month lockdown due to the COVID-19 pandemic was observed in a population of 12889 Chinese youth.

- This study provides evidence for the associations between weight gain and increased sedentary time, COVID-19-related stress and depression score throughout a 4-month lockdown.

- The methods of collecting body weight in the two time periods differed, with the first being under the supervision of professionals, the second being selfadministered due to the constraints of lockdown.

lockdown to halt the spread of the virus, ending on 8 April. All individuals were ordered to stay home or at their residence, except for permitted work and local shopping. All schools, sports facilities, entertainment, recreational venues, personal care and beauty services, and most factories and markets were closed. While this strategy was largely successful, its adverse effects could be of consequence to the health of youth, as for 4 months, they were out of school and, for the most part, stuck in the confines of their homes. ${ }^{1}$

Weight gain during adolescence and early adulthood is associated with a significantly increased morbidity of diabetes and cardiovascular disease, and an increased risk of cardiovascular and all-cause mortality. ${ }^{2}$ The increase in weight is a multifactorial matter. Long-term observational studies and randomised controlled trials have found dietary factors, sedentary behaviours and time spent watching TV were associated with longterm weight gain in healthy populations. ${ }^{45}$

Early evidence has shown that lockdown poses a real threat to psychological well-being, with research citing amplified stress and depression during the COVID-19 pandemic. ${ }^{6}$ Furthermore, in certain countries, there has been a surge in unhealthy 
dietary habits and increased sedentary time, which could be a recipe for increased weight gain. ${ }^{8-10}$ Staying at home for a prolonged period could also support a more sedentary lifestyle and increased time watching TV or other electronic entertainment, along with eating more caloriedense meals, snacking and alcohol consumption. To date, an increasing number of studies have been conducted related to weight change and its associated factors during the COVID-19 lockdown period in various populations, primarily in Europe, and some of those have suggested that behaviour change during the pandemic is a driving force behind weight change. ${ }^{89}$

This dual-centre retrospective observational study aimed to observe weight change in Chinese youth during a 4-month lockdown and the associations between weight change and COVID-19-related stress, anxiety, depression, physical activity, sedentary time and dietary habits.

\section{MATERIALS AND METHODS}

\section{Study design and participants}

This retrospective observational study reviewed 14059 youth (aged 17-27 years) free of chronic diseases from two universities (Hunan Traditional Chinese Medical College, Hunan, China, and Medical College of Jinhua Polytechnic, Zhejiang, China) who measured body weight at the universities before the lockdown, between 1 December 2019 and 20 January 2020. Of these, 13013 participants (response rate of 93.2\%) consented to participate in the present study and completed an online follow-up questionnaire from 1 to 23 May 2020. The participants who replied with questionnaires of poor quality were excluded $(n=124)$. A total of 12889 participants were finally recruited in the study. The criteria of poor quality were as follows: (1) identity (ID) information in the universities' system did not match that in the follow-up questionnaire, and (2) the 81-question survey was completed in less than $3 \mathrm{~min}$. Data from the two time points were linked by identifying each participant's university student ID number and matching them accordingly.

\section{Online follow-up questionnaire}

The online follow-up questionnaire consisted of 81 questions split into four sections: questions regarding characteristic data and perceptions of COVID-19, a questionnaire regarding physical activity and sedentary time, a section regarding meal frequency and alcohol consumption, and questions to assess mental health. The online follow-up questionnaire was sent out to participants and collected via a professional survey platform (https:// www.wjx.cn).

\section{Weight change}

Baseline body weight was measured in accordance with the Chinese National Student Physical Fitness Standard by staff members of the two respective universities for all university students, ${ }^{7}$ using scales and after the removal of shoes/coats, while height was measured using a freestanding height measure. Body mass index (BMI) was calculated and classified according to the Asian cut-off points, classifying overweight as BMI of $\geq 24$ and $<28 \mathrm{~kg}$ / $\mathrm{m}^{2}$, and obesity as BMI of $\geq 28 \mathrm{~kg} / \mathrm{m}^{2}$. Follow-up body weight was measured by participants themselves at home or at a community health centre near their home if no scales were available at home, and was reported to us via the online follow-up questionnaire. Concerning the validity and reliability of determining follow-up body weight, all participants were asked to measure their body weight in the morning right after waking up, in a state of fasting, shoes off, with no large coat. Weight change was calculated by subtracting baseline weight from follow-up weight. Previous studies commonly categorised weight gain as an increase greater than $5 \%$ of body weight from baseline, $10 \%$ for greater increases, ${ }^{11}$ or categorised weight gain as an increase of approximately $3 \mathrm{~kg}$ above baseline. ${ }^{12} 13$ Based on our study population with a mean baseline body weight of $52.3 \pm 9.5 \quad($ mean $\pm \mathrm{SD})$, weight change was classified as no significant change $(-0.9$ to $0.9 \mathrm{~kg})$, mild decrease $(-3.9$ to $-1.0 \mathrm{~kg})$, moderate decrease $(-6.9$ to $-4.0 \mathrm{~kg})$, major decrease $(\leq-7.0 \mathrm{~kg})$, mild increase (1.0 to $3.9 \mathrm{~kg})$, moderate increase (4.0$6.9 \mathrm{~kg})$ and major increase $(\geq 7.0 \mathrm{~kg})$.

\section{Physical activity and sedentary time}

Physical activity and sedentary time were collected through questions regarding exercise prelockdown and during lockdown. These included frequency, duration and intensity of aerobic exercise as well as strength exercise, in a modified version with added items of the Chinese version of the International Physical Activity Questionnaire-Long Form, which had shown adequate reliability and reasonable validity for use in Chinese students. ${ }^{14}$ Exercise volume was expressed in Metabolic equivalent (MET)-hour/week, calculated according to the American College of Sports Medicine (ACSM) metabolic equations prior to and during the lockdown. ${ }^{15}$ Sedentary time, defined as any waking behaviour where energy expenditure is $\leq 1.5$ METs while reclining or sitting, included the number of hours a day spent using a computer or mobile phone ${ }^{15}$ and was expressed as hour/ day. The changes in exercise volume per day and sedentary time per week over the 4-month lockdown were calculated.

\section{Dietary habits}

In this study, food composition was not assessed due to the high participant burden of such a questionnaire and data collection limitations. The present study evaluated meal frequency, including breakfast and lunch frequency, alcohol units per week and snacking times per day at the follow-up time point through a questionnaire based on previous research. ${ }^{16}$ Breakfast and lunch frequency were categorised into three groups: less than once a week, two to six times per week and every day. Snacking was also categorised into three groups: no snacking, snacking once a day (day or late-night) and snacking twice per day (day and late-night). Alcohol habits were recorded as the number of alcohol units. One unit was defined as 
drinking $100 \mathrm{~mL}$ of wine or liquor or one glass/bottle/ can of beer.

\section{Mental health (COVID-19-related stress, depression and anxiety)}

The question used to measure COVID-19-related stress was designed based on previous research ${ }^{17}$ : how concerned are you about yourself or family members/friends being infected by COVID-19? To which the possible answers were none, mild, moderate, major and severe. Two psychological indexes were also used, Becks' Depression Inventory, Second Edition (BDI-II) ${ }^{18}$ validated in young Chinese adults, ${ }^{19} 20$ and the State-Trait Anxiety Inventory (STAI) (Form Y-1), ${ }^{21}$ showing good reliability and validity in Chinese. ${ }^{22}$ In this study, the presence of depression was defined as a BDI-II depression score of $\geq 14,{ }^{20}$ and the presence of anxiety was defined as an STAI score of $49 .^{22}$

\section{Statistical analysis}

The primary outcome of the present study was weight change in Chinese youth during a 4-month lockdown to contain the spread of the COVID-19 pandemic. The secondary outcomes were the associations between the weight change and mental health (COVID-19-related stress, depression and anxiety), changes in physical activity volume and sedentary time, and dietary habits (snacking per day, alcohol consumption and meal frequency per week) during the lockdown.

For analysis of the primary outcome, the changes in body weight, proportions of overweight and obesity were assessed using paired t-test and Wilcoxon signed-rank test accordingly.

For analysis of the secondary outcomes, we initially performed an age-adjusted and baseline body weightadjusted linear regression for the associations between the weight change and mental health, dietary habits, and the changes in physical activity and sedentary time. Then, the associations between the weight change and the potential influencing factors were further assessed by multivariate linear regression in which sex, age, baseline body weight and smoking history were adjusted. Mental health, physical activity, sedentary time and dietary habits were also adjusted in the multivariate linear regression accordingly. To minimise confounding from university (geolocation) and baseline overweight/obesity, university-stratified and BMI-stratified multivariate linear regressions were also performed. Analyses were carried out with the use of SAS software V.9.4; a two-tailed alpha level of 0.05 was considered significant.

\section{Patient and public involvement statement}

No patients or the public were involved in the design, or conduct, or reporting of our research.

\section{RESULTS}

\section{Demographics}

The demographics of 12889 participants are presented in table 1. Participants' ages ranged from 17 to 27 years $(M=19, \mathrm{SD}=1), 80.2 \%$ identified as female. The proportion

Table 1 Demographics and baseline characteristics

\begin{tabular}{|c|c|c|c|c|c|c|}
\hline & \multicolumn{2}{|c|}{ University 1 ( $N=9472)^{*}$} & \multicolumn{2}{|c|}{ University $2(\mathrm{~N}=3417)^{*}$} & \multicolumn{2}{|c|}{ Total $(\mathrm{N}=12889)$} \\
\hline & $\begin{array}{l}\text { Men } \\
(N=1509)\end{array}$ & $\begin{array}{l}\text { Women } \\
\text { (N=7963) }\end{array}$ & $\begin{array}{l}\text { Men } \\
(N=1040)\end{array}$ & $\begin{array}{l}\text { Women } \\
(\mathrm{N}=2377)\end{array}$ & $\begin{array}{l}\text { Men } \\
\text { (N=2549) }\end{array}$ & $\begin{array}{l}\text { Women } \\
(\mathrm{N}=10340)\end{array}$ \\
\hline Age (years) & $19 \pm 1$ & $19 \pm 1$ & $20 \pm 1$ & $20 \pm 1$ & $20 \pm 1$ & $19 \pm 1$ \\
\hline Weight (kg) & $62.3 \pm 10.2$ & $52.0 \pm 7.8$ & $65.0 \pm 10.3$ & $52.2 \pm 7.6$ & $63.4 \pm 10.3$ & $52.0 \pm 7.7$ \\
\hline $\mathrm{BMI}\left(\mathrm{kg} / \mathrm{m}^{2}\right)$ & $21.0 \pm 3.2$ & $20.3 \pm 2.7$ & $21.4 \pm 3.1$ & $20.1 \pm 2.5$ & $21.2 \pm 3.2$ & $20.2 \pm 2.7$ \\
\hline Overweight, n (\%)† & $214(14.5)$ & $1370(17.2)$ & $83(8.0)$ & $140(5.9)$ & $297(11.7)$ & $1510(14.6)$ \\
\hline \multicolumn{7}{|l|}{ Race/ethnicity, n (\%) } \\
\hline Han & $1305(86.5)$ & $6872(86.3)$ & $1040(100)$ & $2377(100)$ & $2345(92.0)$ & $9249(89.4)$ \\
\hline Non-Han & $204(13.5)$ & $1091(13.7)$ & $0(0)$ & $0(0)$ & $204(8.0)$ & $1091(10.6)$ \\
\hline Physical activity (MET-hour/week) & $14.2 \pm 12.5$ & $9.1 \pm 8.5$ & $13.7 \pm 12.2$ & $7.7 \pm 7.3$ & $14.0 \pm 12.3$ & $8.9 \pm 8.3$ \\
\hline Sedentary time (hour/day) & $6.9 \pm 3.4$ & $7.3 \pm 3.4$ & $7.0 \pm 3.2$ & $7.3 \pm 3.3$ & $6.9 \pm 3.3$ & $7.3 \pm 3.4$ \\
\hline $10-15$ cigarettes/day & $45(3.0)$ & $8(0.1)$ & $12(1.1)$ & $1(0.04)$ & $57(2.2)$ & $9(0.09)$ \\
\hline$>15$ cigarettes/day & $29(1.9)$ & $3(0.1)$ & $7(0.7)$ & $1(0.04)$ & $36(1.4)$ & $4(0.03)$ \\
\hline Former smoker & $165(10.9)$ & $130(1.6)$ & $62(6.0)$ & $17(0.7)$ & 227 (8.9) & $147(1.4)$ \\
\hline Never smoke & $1050(69.6)$ & $7756(97.4)$ & $882(84.8)$ & 2351 (98.9) & $1932(75.8)$ & $10107(97.7)$ \\
\hline
\end{tabular}

Data are expressed as mean \pm SD or number (per cent) accordingly. Results were assessed by paired t-test and Wilcoxon signed-rank test accordingly.

*University 1 is Hunan Traditional Chinese Medical College, Hunan province, China; university 2 is Jinhua Polytechnic, Zhejiang province, China.

†Overweight and obesity cut-off points were referred to Asian criteria; overweight is BMI $\geq 24$ and $<28 \mathrm{~kg} / \mathrm{m}^{2}$, and obesity BMI $\geq 28 \mathrm{~kg} / \mathrm{m}^{2}$.

BMI, body mass index. 
of men in the present study is relatively smaller than that of women. We conducted power analysis based on the sample size and primary result (weight change) in the present study for men and women, respectively. For men, a sample size of 2549 achieves $99.9 \%$ power to detect a mean of paired differences of $2.6 \mathrm{~kg}$ with a known SD of differences of $0.6 \mathrm{~kg}$ and a significance level (alpha) of 0.05 using a two-sided paired t-test. For women, a sample size of 10340 achieves $99.9 \%$ power to detect a mean of paired differences of $2.1 \mathrm{~kg}$ with a known SD of differences of $0.3 \mathrm{~kg}$.

\section{Primary outcome}

The median of the subjects' baseline body weight was $62.0 \mathrm{~kg}$, ranging from 39.0 to $95.0 \mathrm{~kg}$ (lowest to highest) in men, and $50.1 \mathrm{~kg}$, ranging from 38.5 to $92.0 \mathrm{~kg}$ in women. The mean absolute and relative changes in weight gain were 2.6 (95\% CI 2.0 to 3.2 ) $\mathrm{kg}$ and $4.2 \%$ (95\% CI $4.0 \%$ to $4.3 \%$ ) for men, and 2.1 (95\% CI 1.9 to 2.4 ) $\mathrm{kg}$ and $4.2 \%$ ( $95 \%$ CI $3.9 \%$ to $4.4 \%$ ) for women, while those in the overall population were 2.2 (95\% CI 2.0 to 2.5 ) and $4.2 \%$ (95\% CI $4.0 \%$ to $4.3 \%)$. There was a significant increase in overweight and obese individuals as a percentage of the population by $4.5 \%$ and $2.7 \%$ in men, and $4.8 \%$ and $3.4 \%$ in women. According to their self-reports, none of the participants of the study was infected with COVID-19. More details are shown in figure $1 \mathrm{~A}-\mathrm{E}$ and online supplemental table 1 .

\section{Secondary outcomes}

Associations between weight change and the changes in physical activity and sedentary time

Sedentary time before the lockdown was $6.9 \pm 3.3$ and $7.3 \pm 3.4$ hours/day in men and women, respectively. There were significant increases in sedentary time in both men (3.9 (95\% CI 3.7 to 4.1) hours/day) and women (3.6 (95\% CI 3.5 to 3.7) hours/day). Exercise volume per week before the lockdown was $14.0 \pm 12.3$ and 8.9 \pm 8.3 MET-hr/wk in men and women, respectively. There was a decrease in men (mean $-0.6,95 \% \mathrm{CI}-1.1$ to -0.1 ) and an increase in women (mean $2.5,95 \%$ CI 2.3 to 2.7). More details are shown in figure $1 \mathrm{~F}, \mathrm{G}$ and online supplemental table 1.

Linear regression results for associations between the weight change and the changes in physical activity and sedentary time are presented in tables 2 and 3. Findings were comparable in direction and magnitude after stratification for BMI of $<24$ and $\geq 24 \mathrm{~kg} / \mathrm{m}^{2}$ and two universities (online supplemental tables 2,3). Categorical analyses of sedentary time revealed similar linear relationships; that is, aggregate change in sedentary time was significantly associated with weight gain in a dose-dependent fashion, with a $1.56 \mathrm{~kg}$ greater weight gain across quartiles (figure 2). The results were consistent when results were evaluated as relative (per cent) weight changes (online supplemental table 4).
Associations between weight change and dietary habits Men (1.8 \pm 2.9 alcohol units) drank more than women $(0.7 \pm 1.6$ alcohol units). The mean difference was 1.2 (95\% CI 1.1 to 1.3$)$. In contrast, the proportion of women who ate snacks at least once per day was significantly greater than men (women vs men, $87.9 \%$ vs $83.2 \%$, $\mathrm{p}<0.001$ ). Only $33.9 \%$ of men and $32.2 \%$ of women had breakfast every day. No significance was found between men and women $(P=0.19)$. In contrast, $98.4 \%$ of men and $98.6 \%$ of women had lunch every day. More details about participants' dietary habits during a 4-month lockdown are shown in online supplemental table 5. In the multivariate linear regression, no significant associations were found between weight change and dietary habits.

\section{Associations between weight change and mental health}

More than one-third of all participants $(34.6 \%$ of men and $42.4 \%$ of women) suffered from COVID-19-related stress in different degrees, and $6.9 \%$ of men and $7.4 \%$ of women responded to having severe stress. The depression score obtained from BDI-II was $5 \pm 8$ (mean \pm SD) and $6 \pm 8$ in men and women, respectively. Here the STAI anxiety score was $39 \pm 10$, both in men and women. More details about participants' mental health during the 4-month lockdown are shown in online supplemental table 5. Increased COVID-19-related stress and BDI-II depression score were significantly associated with weight gain. Detailed results are presented in tables 2 and 3 and figure 2. Findings were comparable in direction and magnitude after stratification for BMI and two universities (online supplemental tables 2,3), and were also similar when evaluated as relative weight changes (online supplemental table 4).

\section{DISCUSSION}

Longitudinal studies have shown that the average yearly weight gain in general populations is approximately $0.45 \mathrm{~kg}$ a year. ${ }^{4}$ This study observed a significant weight gain, an increase of 2.2 (95\% CI 2.2 to 2.3$) \mathrm{kg}$, over a 4-month lockdown period in Chinese youth. A sharp increase in weight has been associated with an increase in blood pressure. ${ }^{23}$ Even more moderate increases over a longer period are associated with chronic diseases, ${ }^{24}$ all of which are exacerbated when weight is gained during adolescence and early adulthood to have later life repercussions. ${ }^{25}{ }^{26}$ The interruption of individual routines and confinement may lead to a calorie imbalance pushed by concomitant lower physical activity and increased sedentary time, as well as irregular eating patterns and frequent snacking. This study provides evidence for the associations between weigh gain and increased sedentary time, COVID-19-related stress and depression score over the span of a 4-month lockdown.

Limited mobility of the general public, as a consequence of lockdowns around the world, has yielded undesired effects of more prevalent sedentary behaviour ${ }^{27}$ that comprise very little calorific demand. ${ }^{28}$ Sedentary time in 
A

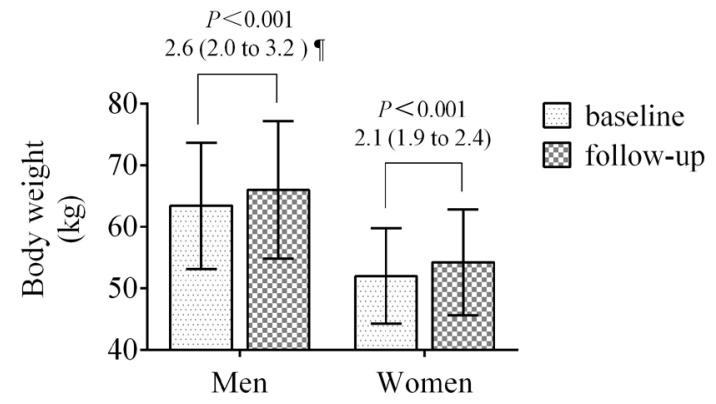

B

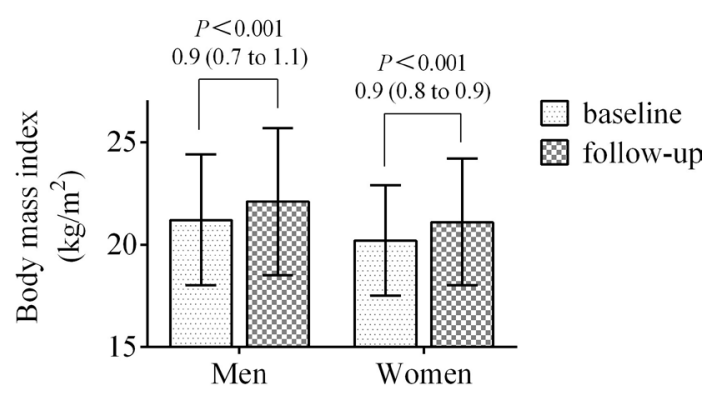

C

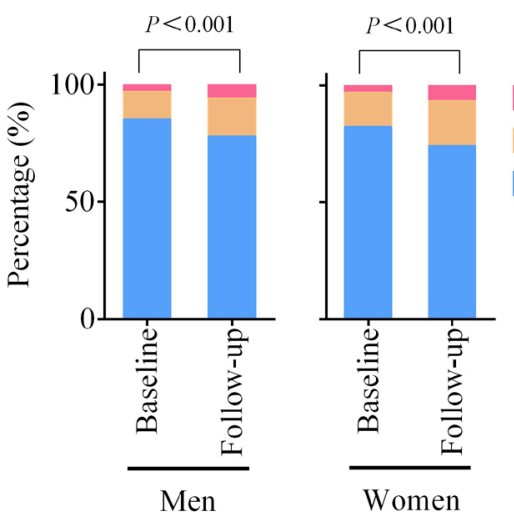

BMI $\geq 28$ (Obesity)

$24 \leq \mathrm{BMI}<28$ (Overweight)

$\mathrm{BMI}<24$
D Change in body weight (men)

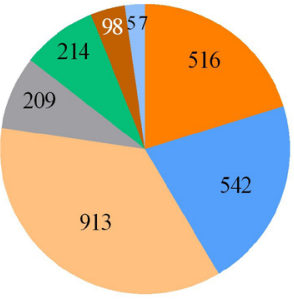

Total $=2,549$

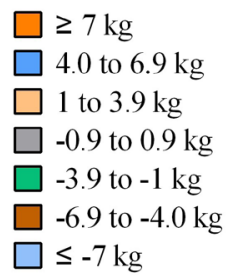

$\leq-7 \mathrm{~kg}$

$\mathrm{E}$ Change in body weight (women)

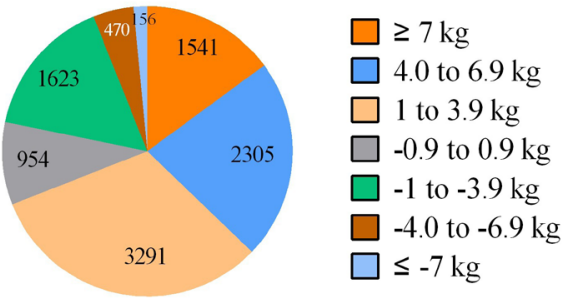

Total $=10,340$

G

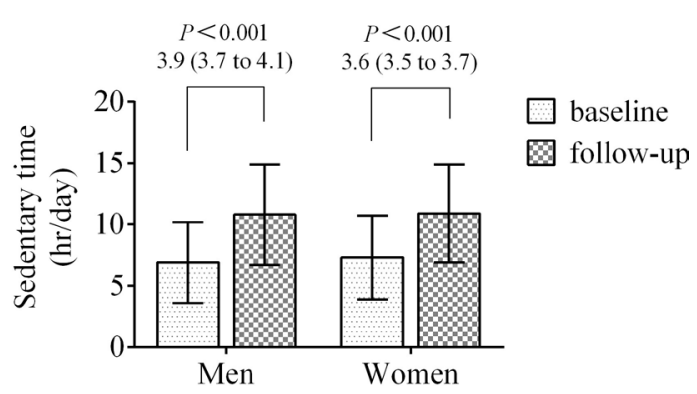

Figure 1 Changes in body weight (A), BMI (B), the proportion of overweight and obesity (C), weight gain as a proportion in men $(D)$ and women $(E)$, exercise volume per week $(F)$ and sedentary time per day $(G)$ over the 4-month lockdown. The line indicates the mean, and the error bar indicates the SD. The results were assessed by paired t-test and Wilcoxon signed-rank test were used accordingly. ๆMean difference and $95 \% \mathrm{Cl}$. BMI, body mass index. 


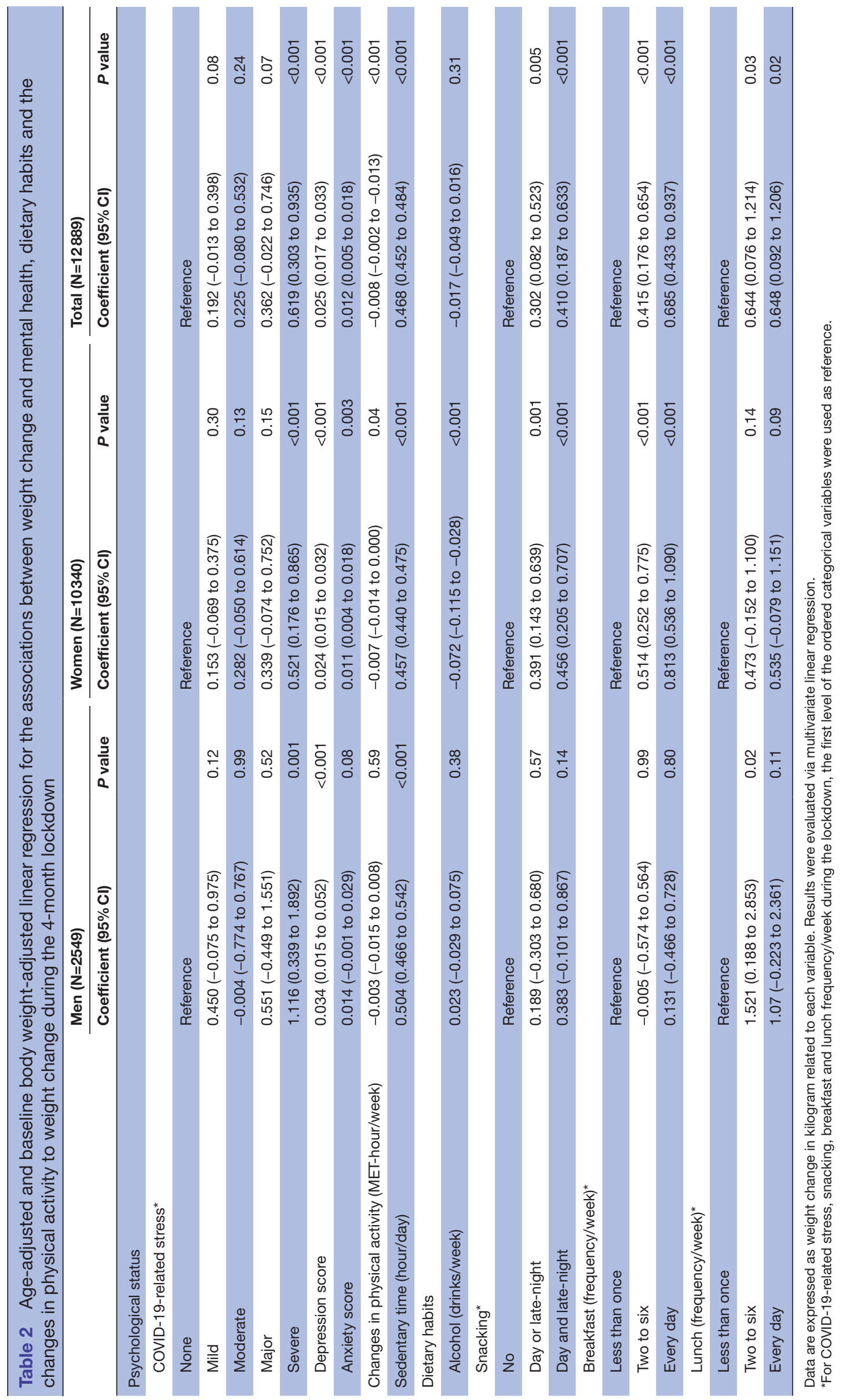


Table 3 Multivariate linear regression for the associations between weight change and COVID-19-related stress, depression score and the change in sedentary time during the 4-month lockdown

\begin{tabular}{|c|c|c|c|c|c|c|}
\hline & \multicolumn{2}{|l|}{ Men (N=2549) } & \multicolumn{2}{|l|}{ Women $(\mathrm{N}=10340)$} & \multicolumn{2}{|l|}{ Total $(\mathrm{N}=12889)$} \\
\hline & Coefficient $(95 \% \mathrm{Cl})$ & $P$ value & Coefficient $(95 \% \mathrm{Cl})$ & $P$ value & Coefficient $(95 \% \mathrm{Cl})$ & $P$ value \\
\hline \multicolumn{7}{|l|}{ COVID-19-related stress* } \\
\hline Mild & $0.184(-0.309$ to 0.677$)$ & 0.82 & $-0.035(-0.239$ to 0.170$)$ & 0.99 & $-0.015(-0.205$ to 0.176$)$ & 0.99 \\
\hline Moderate & $-0.320(-1.063$ to 0.423$)$ & 0.73 & $0.049(-0.259$ to 0.356$)$ & 0.99 & $-0.025(-0.310$ to 0.261$)$ & 0.99 \\
\hline $\begin{array}{l}\text { Change in sedentary time } \\
\text { (hour/day) }\end{array}$ & $0.530(0.490$ to 0.571$)$ & $<0.001$ & $0.463(0.446$ to 0.481$)$ & $<0.001$ & $0.476(0.460$ to 0.492$)$ & $<0.001$ \\
\hline Depression score & $0.023(0.001$ to 0.047$)$ & 0.04 & $0.019(0.008$ to 0.030$)$ & 0.001 & $0.017(0.007$ to 0.027$)$ & 0.001 \\
\hline
\end{tabular}

Data are expressed as weight change in kilogram related to each variable. Results were evaluated via multivariate linear regression.

${ }^{*}$ For COVID-19-related stress, no stress was a reference.

our population of Chinese youth increased and was associated with increased weight. These findings are consistent with prior research showing sedentary behaviour, TV viewing and computer use being risk factors for the increased weight ${ }^{29} 30$ and consistent with similar observations in Europe ${ }^{31}$ A possible reason behind this may be due to the general restraint to one's home and the greater availability of free time without requiring active travel to school/work. In addition, increased sedentary time is likely due to a combination of boredom, free time, distance learning and online social activity. ${ }^{31}$

In the present study, exercise volume was associated with weight change in women alone, possibly due to the low exercise volume both before and during the lockdown, far below the ACSM-recommended exercise volume (16.7 MET-hours/week), ${ }^{15}$ and the change in exercise volume in the overall population being small. Various studies have looked into physical activity. While there is some disagreement within population cohorts, in university students, exercise habits are largely mediated by time constraints, ${ }^{32}$ where students perceive limited time as a primary reason for not exercising. Also, adherence to exercise is often extrinsic, particularly in youth, where exercisers do so because of physical appearance, weight gain and stress management, adding plausibility that exercise may have been increased as management for perceived weight gain and/or stress and due to more available time. Exercise, particularly high-intensity interval training, can bring about great improvements in reducing body fat, improving body composition ${ }^{33}$ and reductions in associated health complications including metabolic syndrome and insulin resistance, ${ }^{3435}$ and therefore is an activity that is encouraged, particularly during the lockdown.

Weight gain also comes through increased intake of calorie-rich food, large portions and dependent on food composition, ${ }^{36}$ leading to weight gain. The COVID-19 pandemic may pose a notable dietary risk exacerbated by the confinement to the home for a prolonged period, often with greater access to food. Across multiple populations around the world, there have been studies showing significant changes in dietary habits during the lockdown. In the UK, as many as $48 \%$ of research participants reported increased food intake ${ }^{37}$ and increased detrimental dietary practices, echoed throughout the world, ${ }^{38} 39$ with research reporting an increase in snacking and eating in response to smell and sight. ${ }^{10}$ Increased problematic eating behaviours such as increased snacking, as seen in the present study, may result in an increase in fat mass and percentage due to higher calorie intake. This study observed that snacking frequency per day was positively related to weight gain in women alone.

COVID-19 lockdowns can greatly affect the social environment of youths. According to Androutsos et $a \hat{l}^{1}$ $5.1 \%$ of mothers and $2.9 \%$ of fathers of those surveyed in Greece had lost their jobs, which could affect stress levels of the immediate family. In addition, during the initial lockdown, the continuous hearing and constant news coverage on the spread of COVID-19 and mortality associated with it can be stressful. ${ }^{40}$ Since then, evidence has been accumulating that lockdown conditions have increased the prevalence of depression, anxiety and stress across multiple populations. ${ }^{41}{ }^{42}$ Stressful life events, such as university/school-related stress, are known to be associated with weight gain. ${ }^{43}$ We found that severe stress over COVID-19 was associated with considerable weight gain in women and men. During this pandemic, a significantly high percentage of survey respondents reported increased eating as a response to stress and sleep deprivation during the quarantine, as reported by Zachary et al. ${ }^{10}$ In various people, the manifestation of stress or an emotional disturbance may lead to a resulting coping mechanism of increasing the consumption of energy-dense foods. ${ }^{44}$ Stress is also thought to affect PA. A comprehensive review found the majority of 55 longitudinal studies supported an association between stress and lower levels of PA. ${ }^{45}$

Social isolation and confinement are possible routes towards depression. ${ }^{46}$ BDI-II depression score was associated with increased weight gain. This is in agreement 
A

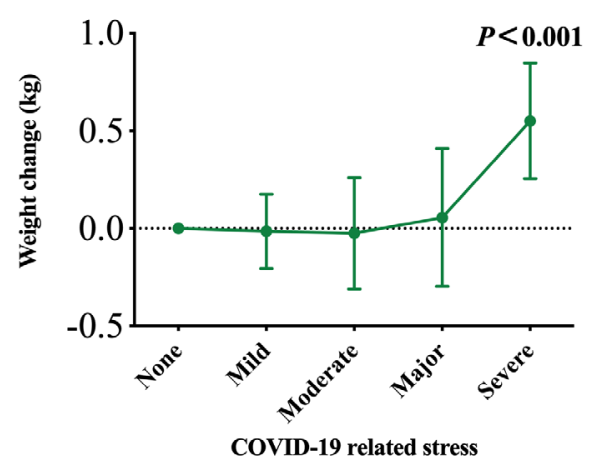

B

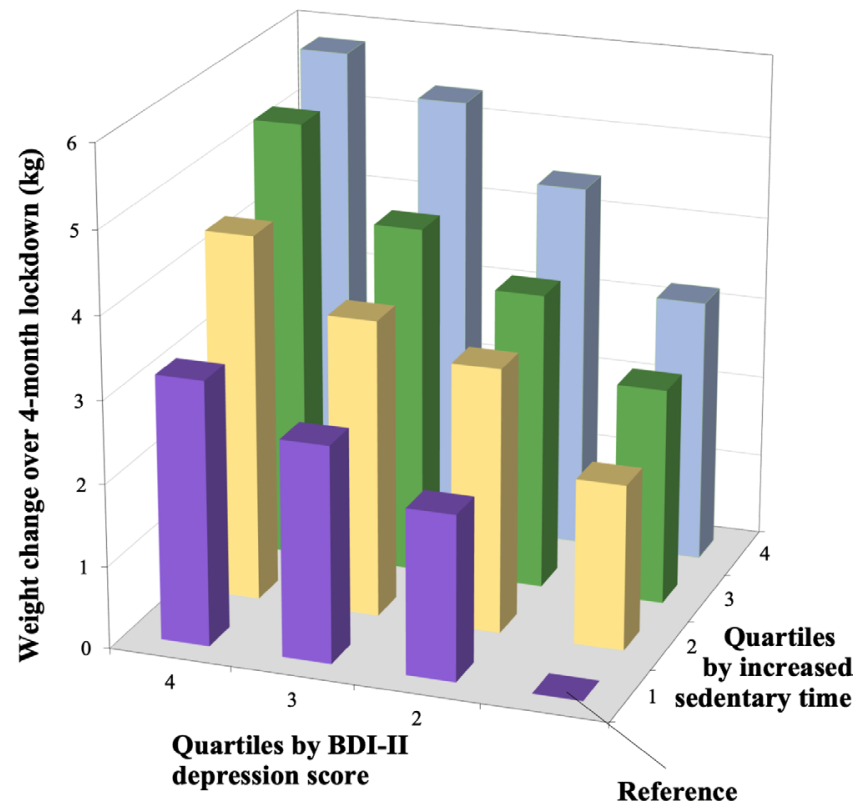

Figure 2 (A) The relationship between COVID-19-related stress and weight change; $p<0.001$ for comparison between no stress and severe stress was assessed by Wilcoxon signed-rank test. (B) The relationship between the crossstratified quartiles of changes in sedentary time and depression score in ascending order with weight changes. As compared with individuals in the lowest quartiles of both sedentary time and depression score, individuals in the highest quartiles had a $5.82 \mathrm{~kg}$ greater weight gain $(P<0.001,95 \% \mathrm{Cl} 5.37$ to 6.27$)$, evaluated via multivariate linear regression. $P<0.001$ for all comparisons. BDI-II, Becks' Depression Inventory, Second Edition.

with a consortium of previous studies whereby depression appears to have a significant effect on short-term and longterm weight gain. ${ }^{478}$ Anxiety was a minimal contributor to weight gain in women, but not in men, and appears to be more commonly present in women, which supports previous studies that state anxiety appears to affect women during the pandemic more than men. ${ }^{49}$ While stress and depression may affect sedentary behaviour, these relationships are likely bidirectional, whereby an increase in sedentary behaviour may also increase stress elements and depression.

\section{Limitations}

There are several limitations to this study. The methods of collecting weight in the two time periods differed, with the first being under the supervision of professionals and the second being self-administered due to the constraints of lockdown. While instructions were given to participants regarding how and when to weigh themselves, measurement errors as well as overestimation/underestimation may occur to some degree. Although breakfast and lunch frequency, snacking and alcohol intake were observed, this study did not report on dietary composition due to the heavy burden on participants, particularly in Chinese cuisine, which involves several dishes per meal. Due to limitations in research, we have no data representative of yearly or semesterly weight gain in Chinese university students to compare our results with. Psychological status of depression and anxiety was collected at the second time point only; therefore, causality may not be established from these.

Furthermore, just as with any medical intervention or organic finding, the results represent the average public effect, and variations within individuals exist. The present retrospective study only observed a 4-month lockdown that resulted from the COVID-19 pandemic, and primarily comprised Han, university-educated Chinese youth, which potentially limited the generalisability of the findings. However, our findings were consistent among two universities, sex and individuals with BMI of $<24$ and $\geq 24 \mathrm{~kg} / \mathrm{m}^{2}$, with multivariable adjustment. All results remained persistent in additional analyses when weight change was evaluated as relative weight changes. It seems plausible that the biological effects of many factors would be qualitatively similar in other populations.

\section{CONCLUSION}

There was a significant weight gain in the Chinese youth during a 4-month lockdown. The weight gain was associated with increased sedentary time, COVID-19-related stress and depression. These findings suggest that interventions to decrease sedentary time and improve mental health may be warranted to mitigate weight gain during the lockdown period and reverse the weight gain in youth after the COVID-19 pandemic.

\section{Author affiliations}

${ }^{1}$ Division of Cardiac Rehabilitation, Department of Physical Medicine and Rehabilitation, Xiangya Hospital of Central South University, Changsha, Hunan, China

${ }^{2}$ National Clinical Research Center for Geriatric Disorders, Xiangya Hospital of Central South University, Changsha, Hunan, China

${ }^{3}$ Department of Cardiovascular Medicine, Mayo Clinic, Rochester, Minnesota, USA ${ }^{4}$ Department of Internal Medicine, Hunan Traditional Chinese Medical College, Zhuzhou, Hunan, China

${ }^{5}$ Medical College, Jinhua Polytechnic, Jinhua, Zhejiang, China

Acknowledgements We thank all participants and investigators in participating centres and also Jiabi Qin and Jing Deng (Xiangya School of Public Health, Central South University, Hunan, China), who provided advice on the statistical analysis plan. 
Contributors SL, YDu and JWR conceived the study. SL and YDu were involved in securing funding for the study. NZ, BY, WZ, YDo, JL, HL and QL coordinated the study conduct and data collection. YDu did the study analyses, supervised by SL. YDu and JWR wrote the article, with assistance from RJT, TPO, BY, QL, HL and SL. All authors approved the final version of the manuscript. SL had full access to all the data in the study and had the final responsibility for the decision to submit for publication.

Funding This study is supported by Hunan Development and Reform Commission Foundation of China (number (2012)1521 to SL) and The Youth Science Foundation of Xiangya Hospital (grant number 2019003 to YDu).

Competing interests None declared.

\section{Patient consent for publication Not required.}

Ethics approval This study received ethical approvals from the medical ethics committee of Xiangya Hospital of Central South University (approval number 202005126); the medical ethics committee of Medical College of Jinhua Polytechnic (approval number 20200010); and the medical ethics committee of Hunan Traditional Chinese Medical College (approval number 20200032). All participants gave electronic consent before enrolment in the study, which was conducted in accord with the principles of the Declaration of Helsinki. Participants were anonymized and codified to protect their personal information.

Provenance and peer review Not commissioned; externally peer reviewed.

Data availability statement Data are available upon reasonable request. The data that support the findings of this study are available on request from the corresponding author, SL.

Supplemental material This content has been supplied by the author(s). It has not been vetted by BMJ Publishing Group Limited (BMJ) and may not have been peer-reviewed. Any opinions or recommendations discussed are solely those of the author(s) and are not endorsed by BMJ. BMJ disclaims all liability and responsibility arising from any reliance placed on the content. Where the content includes any translated material, BMJ does not warrant the accuracy and reliability of the translations (including but not limited to local regulations, clinical guidelines, terminology, drug names and drug dosages), and is not responsible for any error and/or omissions arising from translation and adaptation or otherwise.

Open access This is an open access article distributed in accordance with the Creative Commons Attribution Non Commercial (CC BY-NC 4.0) license, which permits others to distribute, remix, adapt, build upon this work non-commercially, and license their derivative works on different terms, provided the original work is properly cited, appropriate credit is given, any changes made indicated, and the use is non-commercial. See: http://creativecommons.org/licenses/by-nc/4.0/.

\section{ORCID iD}

Suixin Liu http://orcid.org/0000-0001-7621-0096

\section{REFERENCES}

1 King AJ, Burke LM, Halson SL, et al. The challenge of maintaining metabolic health during a global pandemic. Sports Med 2020;50:1233-41.

2 Yang Y, Dugué P-A, Lynch BM, et al. Trajectories of body mass index in adulthood and all-cause and cause-specific mortality in the Melbourne Collaborative cohort study. BMJ Open 2019;9:e030078.

3 Zheng Y, Manson JE, Yuan C, et al. Associations of weight gain from early to middle adulthood with major health outcomes later in life. JAMA 2017:318:255-69.

4 Mozaffarian D, Hao T, Rimm EB, et al. Changes in diet and lifestyle and long-term weight gain in women and men. $N$ Engl J Med 2011;364:2392-404.

5 Raynor HA, Steeves EA, Bassett DR, et al. Reducing TV watching during adult obesity treatment: two pilot randomized controlled trials. Behav Ther 2013;44:674-85.

6 Wang C, Pan R, Wan X, et al. Immediate psychological responses and associated factors during the initial stage of the 2019 coronavirus disease (COVID-19) epidemic among the general population in China. Int J Environ Res Public Health 2020;17:1729-85.

7 Dun Y, Ripley-Gonzalez JW, Zhou N, et al. The association between prior physical fitness and depression in young adults during the COVID-19 pandemic-a cross-sectional, retrospective study. PeerJ 2021;9:e11091.

8 Kriaucioniene V, Bagdonaviciene L, Rodríguez-Pérez C, et al. Associations between changes in health behaviours and body weight during the COVID-19 quarantine in Lithuania: the Lithuanian COVIDiet study. Nutrients 2020;12:3119.

9 Flanagan EW, Beyl RA, Fearnbach SN, et al. The impact of COVID-19 stay-at-home orders on health behaviors in adults. Obesity 2021;29:210-6.

10 Zachary Z, Brianna F, Brianna L, et al. Self-quarantine and weight gain related risk factors during the COVID-19 pandemic. Obes Res Clin Pract 2020;14:210-6.

11 Playdon MC, Bracken MB, Sanft TB, et al. Weight gain after breast cancer diagnosis and all-cause mortality: systematic review and meta-analysis. J Natl Cancer Inst 2015;107:djv275.

12 Reiner M, Niermann C, Jekauc D, et al. Long-term health benefits of physical activity--a systematic review of longitudinal studies. BMC Public Health 2013;13:813.

13 Sánchez E, Lecube A, Bellido D, et al. Leading factors for weight gain during COVID-19 Lockdown in a Spanish population: a crosssectional study. Nutrients 2021:13:894.

14 Macfarlane D, Chan A, Cerin E. Examining the validity and reliability of the Chinese version of the International physical activity questionnaire, long form (IPAQ-LC). Public Health Nutr 2011;14:443-50.

15 Riebe D, Ehrman JK, Liguori G. ACSM's guidelines for exercise testing and prescription. Philadelphia: Wolters Kluwer, 2018

16 McCrory MA, Campbell WW. Effects of eating frequency, snacking, and breakfast skipping on energy regulation: symposium overview. $J$ Nutr 2011;141:144-7.

17 Goodwin R, Gaines SO, Myers L, et al. Initial psychological responses to swine flu. Int J Behav Med 2011;18:88-92.

18 Beck AT, Steer RA, Brown GK. Manual for the Beck depression inventory-II. San Antonio: Psychological Corporation, 1996: 1-82.

19 Yang X, Stewart SM. The Beck Depression Inventory-II as a screening tool of depression in the Chinese adolescent population in Hong Kong: a validation study using the composite international diagnostic interview as the gold standard. Asian J Psychiatr 2020;52:102125

20 Zhu J, Zhang J, Sheng Z, et al. Reliability and validity of the Beck depression Inventory-II applied to Chinese construction workers. Soc Behav Pers 2018;46:249-58.

21 Spielberger CD, Gorsuch R, Lushene RE. Manual for the state-trait anxiety inventory (form Y1 - Y2), 1968. Available: http://oml.eular org/sysModules/obxOml/docs/ID_150/State-Trait-Anxiety-\%2023\% 20Inventory.pdf

22 Shek DT. The Chinese version of the state-trait anxiety inventory: its relationship to different measures of psychological well-being. $J$ Clin Psychol 1993;49:349-58.

23 Covassin N, Sert-Kuniyoshi FH, Singh P, et al. Experimental weight gain increases ambulatory blood pressure in healthy subjects: implications of visceral fat accumulation. Mayo Clin Proc 2018;93:618-26.

24 Lv J, Fan B, Wei M, et al. Trajectories of early to mid-life adulthood $\mathrm{BMI}$ and incident diabetes: the China health and nutrition survey. BMJ Open Diabetes Res Care 2020;8:e000972.

25 van der Baan-Slootweg O, Benninga MA, Beelen A, et al. Inpatient treatment of children and adolescents with severe obesity in the Netherlands: a randomized clinical trial. JAMA Pediatr 2014;168:807-14.

26 Daniels SR, Pratt CA, Hayman LL. Reduction of risk for cardiovascular disease in children and adolescents. Circulation 2011;124:1673-86.

27 Chen P, Mao L, Nassis GP, et al. Coronavirus disease (COVID-19): the need to maintain regular physical activity while taking precautions. $J$ Sport Health Sci 2020:9:103-4.

28 Bonn SE, Rimm EB, Matthews CE, et al. Associations of sedentary time with energy expenditure and anthropometric measures. Med Sci Sports Exerc 2018;50:2575-83

29 Ashdown-Franks G, Vancampfort D, Firth J, et al. Leisure-Time Sedentary Behavior and Obesity Among 116,762 Adolescents Aged 12-15 Years from 41 Low- and Middle-Income Countries. Obesity 2019;27:830-6.

30 Guo C, Zhou Q, Zhang D, et al. Association of total sedentary behaviour and television viewing with risk of overweight/obesity, type 2 diabetes and hypertension: a dose-response meta-analysis. Diabetes Obes Metab 2020;22:79-90.

31 Androutsos O, Perperidi M, Georgiou C, et al. Lifestyle changes and determinants of children's and adolescents' body weight increase during the first COVID-19 Lockdown in Greece: the COV-EAT study. Nutrients 2021;13:930.

32 Ebben W, Brudzynski L. Motivations and barriers to exercise among college students. JEP online 2008;11:1-11 https://www.asep.org/ asep/asep/EbbenJEPonlineOctober2008.pdf 
33 Dun Y, Thomas RJ, Medina-Inojosa JR, et al. High-Intensity interval training in cardiac rehabilitation: impact on fat mass in patients with myocardial infarction. Mayo Clin Proc 2019;94:1718-30.

34 Li H, Dun Y, Zhang W, et al. Exercise improves lipid droplet metabolism disorder through activation of AMPK-mediated lipophagy in NAFLD. Life Sci 2021;273:119314.

35 Dun Y, Thomas RJ, Smith JR, et al. High-intensity interval training improves metabolic syndrome and body composition in outpatient cardiac rehabilitation patients with myocardial infarction. Cardiovasc Diabetol 2019;18:104.

36 Zhou B, Ichikawa R, Parnell LD, et al. Metabolomic links between sugar-sweetened beverage intake and obesity. $J$ Obes 2020;7154738:1-10.

37 Buckland NJ, Swinnerton LF, Ng K, et al. Susceptibility to increased high energy dense sweet and savoury food intake in response to the COVID-19 lockdown: the role of craving control and acceptance coping strategies. Appetite 2021;158:105017.

38 Cheikh Ismail L, Osaili TM, Mohamad MN, et al. Eating habits and lifestyle during COVID-19 Lockdown in the United Arab Emirates: a cross-sectional study. Nutrients 2020;12:3314.

39 Di Renzo L, Gualtieri P, Pivari F, et al. Eating habits and lifestyle changes during COVID-19 lockdown: an Italian survey. J Trans/ Med 2020;18:229.

40 Muscogiuri G, Barrea L, Savastano S, et al. Nutritional recommendations for CoVID-19 quarantine. Eur J Clin Nutr 2020;74:850-1.
41 Brooks SK, Webster RK, Smith LE, et al. The psychological impact of quarantine and how to reduce it: rapid review of the evidence. Lancet 2020;395:912-20.

42 Dubey S, Biswas P, Ghosh R, et al. Psychosocial impact of COVID-19. Diabetes Metab Syndr 2020;14:779-88.

43 Serlachius A, Hamer M, Wardle J. Stress and weight change in university students in the United Kingdom. Physiol Behav 2007;92:548-53.

44 Mattioli AV, Sciomer S, Cocchi C, et al. Quarantine during COVID-19 outbreak: changes in diet and physical activity increase the risk of cardiovascular disease. Nutr Metab Cardiovasc Dis 2020;30:1409-17.

45 Stults-Kolehmainen MA, Sinha R. The effects of stress on physical activity and exercise. Sports Med 2014;44:81-121.

46 Matthews T, Danese A, Wertz J, et al. Social isolation, loneliness and depression in young adulthood: a behavioural genetic analysis. Soc Psychiatry Psychiatr Epidemiol 2016;51:339-48.

47 Konttinen H, van Strien T, Männistö S, et al. Depression, emotional eating and long-term weight changes: a population-based prospective study. Int J Behav Nutr Phys Act 2019;16:28.

48 Grundy A, Cotterchio M, Kirsh VA, et al. Associations between anxiety, depression, antidepressant medication, obesity and weight gain among Canadian women. PLoS One 2014;9:e99780.

49 Wang C, Pan R, Wan X, et al. Immediate psychological responses and associated factors during the initial stage of the 2019 coronavirus disease (COVID-19) epidemic among the general population in China. Int J Environ Res Public Health 2020;17:1729. 